\title{
Trial of a method of self-screening for gonorrhoea suitable for apprehensive girls
}

\author{
ELIZABETH BARRETT-CONNOR, JAMES D. CONNOR, LEE ELGIN, AND \\ MICHAEL W. KIMBERLY \\ From the Departments of Community Medicine and Pediatrics, University of California, San Diego School of \\ Medicine and the Dade County Public Health Department, Miami, Florida, U.S.A.
}

Over two million new gonorrhoea infections occur annually in the United States according to a recent estimate (American Social Health Association, 1971). Over half all reported cases occur in the 16 per cent. of the population which is less than 25 years of age, with a high rate in the 10 to 19 -year age group. The reluctance of adolescents to seek medical care for sexually acquired disease, together with the usual asymptomatic nature of infection in females, potentiates the problem. The diagnosis and treatment of asymptomatic school girl carriers would serve the important dual function of reducing the source of infection and preventing serious sequelae. This paper describes the preliminary evaluation of a diagnostic method which requires neither direct medical supervision nor a pelvic examination.

\section{Methods}

Women referred to the Dade County Public Health Department with a presumptive diagnosis of gonorrhoea, based on a positive contact history, symptoms, or both, were studied in anticipation of a high yield of positive cultures. These patients were given a blunt-ended plastic pipette with a rubber bulb (Figure). They were instructed by a public health nurse to insert the pipette into the

Received for publication November 23, 1971

Please address correspondence to: Elizabeth Barrett-Connor, M.D., Department of Community Medicine, University of California, San Diego School of Medicine, Salk Surge Facility No. 2, La Jolla, California 92037, U.S.A. vagina as far as it would comfortably go, compress the bulb several times, and then withdraw the pipette. They were then to compress the bulb several times with the tip in a tube of sterile carrier broth, discard the pipette, and return the covered tube to the nurse. After receiving these instructions the patient performed the procedure without observation or further assistance. Immediately after this procedure a swab from the cervix, obtained under direct visualization at pelvic examination, was placed in a similar tube of sterile broth for transport to the laboratory. Both specimens were received in the laboratory within four hours.

The material obtained from the pipette and that obtained by direct cervical examination were both cultured on Thayer-Martin media containing vancomycin-colistinnystatin inhibitors (Thayer and Martin, 1966). Material obtained under direct cervical visualization was transferred from the original swab directly to the solid media. Samples from the first eighteen pipette specimens were transferred by loop; subsequent specimens were transferred by swab. Bacterial colonies that showed a positive oxidase reaction and Gram-negative diplococci on the selective media were considered to be Neisseria gonorrhoeae. A comparison of the culture results of both methods was made.

\section{Results}

A series of 47 females aged 13 to 40 years with a history of gonorrhoeal contact, symptoms, or both, was seen. Eighteen were aged 18 years or less; they were considered to be teenagers for purposes of this discussion. Symptoms were reported in only

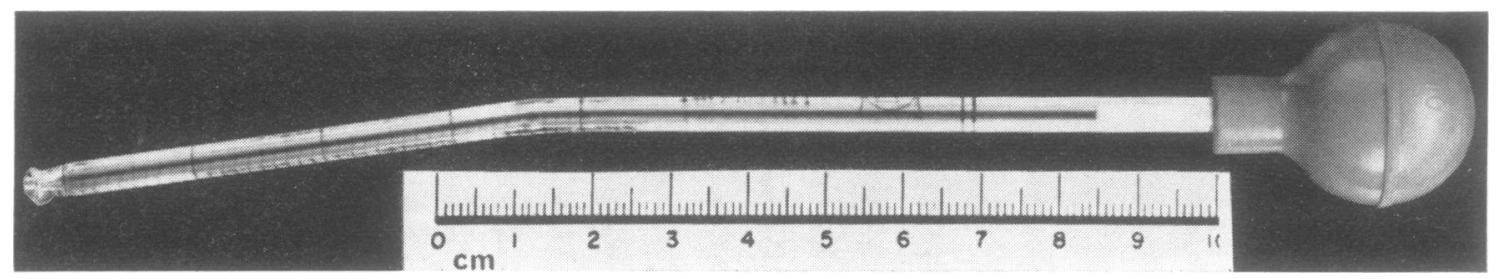

F I GURE Plastic pipette for vaginal insertion 
one-third of patients regardless of age (four of 18 teenagers; ten of 29 adults).

Fifteen patients had negative cultures for gonorrhoea by one or both methods; in five of these cases overgrowth of culture media with non-gonococcal organisms from one or both sources occurred.

In 32 patients a diagnosis of gonorrhoea was confirmed by culture (Table I). Seventeen of these patients had a positive culture by the pipette method; two of these had a simultaneous negative culture obtained by direct cervical examination, and one

TABLE I Results of cultures for N. gonorrhoeae taken by direct cervical swab v. pipette method

\begin{tabular}{lll}
\hline $\begin{array}{l}\text { Total no. with } \\
\text { positive culture by } \\
\text { one or both methods }\end{array}$ & $\begin{array}{l}\text { No. with cervical } \\
\text { swab positive } \\
\text { culture }\end{array}$ & $\begin{array}{l}\text { No. with pipette } \\
\text { positive culture }\end{array}$ \\
$32 / 47$ (68 per cent.) & $\begin{array}{l}29 / 47 \text { (61 per } \\
\text { cent.) }\end{array}$ & $\begin{array}{l}1747 \text { (36 per } \\
\text { cent.) }\end{array}$ \\
\hline
\end{tabular}

aDenominator is total number of patients cultured by both methods

additional patient refused pelvic examination. Nine patients with a positive cervical culture had a negative pipette culture and six other patients with positive cervical cultures had overgrowth of the pipette culture. Positive pipette specimens transferred by loop to solid media showed relatively few colonies of Neisseria gonorrhoeae (usually less than 10); pipette specimens transferred by swab showed a heavier growth of gonococci when positive, but overgrowth with non-gonococcal organisms was more frequent. Overgrowth of material obtained by pipette occurred in two of eighteen instances in which the broth to specific medium transfer was made by loop and in eight of 29 instances in which a swab was used. Overgrowth was not related to the presence or absence of symptoms.

When the results were analysed by age; it was seen that in teenagers the pipette method appears to be equal in value to the direct cervical swab for yield of gonococcal cultures (Table II). Nine of eighteen patients with positive results from pipette cultures were teenagers, and only four of the fifteen

TABLE II Results of cultures for N. gonorrhoeae taken by direct cervical swab $v$. pipette method in teenagers

${ }^{a}$ No. with cervical swab positive culture

No. with pipette positive culture

$10 / 18$ (56 per cent.)

918 (50 per cent.)

a Denominator is total number of teenage cases cultured

Note: Two teenagers had positive pipette and negative cervical swab cultures. A third teenager with a positive pipette culture refused pelvic examination 'missed' cases were 18 years of age or less. No association between positive or negative culture results and the presence or absence of symptoms was noted.

\section{Discussion}

In 1970 there were 573,200 reported cases of gonorrhoea in the United States, a 16 per cent. increase over the previous year (ASHA, 1971). The gonorrhoea rate for teenagers is disproportionately high; based on known cases, one in every 250 boys and girls contracted gonorrhoea in 1967 (Kampmeier, 1968). Unreported or undiagnosed disease among adolescents is probably even greater than in the general population, where it is estimated that known disease represents only one-fourth of the true annual incidence of gonorrhoea.

Ignorance, indifference, shame, and the asymptomatic nature of infection combine to minimize medical care for teenage girls, who then serve as a major source of endemic gonorrhoea. When teenage girls are seen by a physician sexual contact history is seldom sought and pelvic examination is seldom performed in the absence of specific symptoms (Merril, 1968). Even when such examination is performed, the possibility of gonorrhoea may not be considered. Unmarried girls may refuse pelvic examination, and, even when acceptable, the procedure is too expensive and time-consuming to be feasible for large-scale screening purposes.

The pipette method described here was designed to provide an easy, inexpensive, and reliable method for detecting asymptomatic gonorrhoea in women who might otherwise not seek or receive appropriate medical care. In this series pipetted cultures showed an overall effectiveness of only 56 per cent when compared with cervical cultures obtained at direct examination, but among the thirteen teenagers with gonorrhoea the pipette method was diagnostic in 70 per cent. No currently employed microbiological technique detects all cases of gonorrhoea in infected women, even when specimens from multiple sites are obtained by careful speculum examination (Schmale Martin, and Domescik, 1969), and these figures compare reasonably well with the 50 to 85 per cent. positivity rate in single vaginal specimens obtained by pelvic examination of known contacts by otherworkers (Martin, Billings, Hackney, and Thayer, 1967; Lucas, Price, Thayer, and Schroeter, 1967; Caldwell, Price, Pazin, and Cornelius, 1971). A frequent reason for pipette-method failure in this series was due to overgrowth of other bacteria encountered during insertion of the pipette, a problem which might well be lessened by the addition of 
trimethoprim to the culture medium as recently described (Seth, 1970). The use of improved transport media, available since this study was carried out (Martin and Lester, 1971), would also make feasible the application of self-testing pipette techniques at a distance from the laboratory.

Although these numbers are small, they suggest that this method merits further evaluation as a technique in preventive medicine. It should be apparent that if the current gonorrhoea rate is to be reduced, detection of asymptomatic teenage girls who serve as sources of infection is necessary. Particular effort should be directed towards girls who refuse pelvic examination, girls whose physicians are reluctant to perform pelvic examination, and those from groups with no usual sources of medical care. The pipette technique described here can be done without pelvic examination or direct supervision. Its insertion is as simple and as safe as the insertion of a tampon. This technique could be used by private physicians, public health authorities, and school nurses in endemic areas. This method is not intended to supersede the pelvic examination which may detect other coexisting diseases, but to fill a serious epidemiological gap in the control of gonorrhoea.

\section{Summary}

A series of 47 women with symptoms or a history of gonorrhoeal contact were examined bacteriologically for gonorrhoeal infection. Specimens obtained by a plastic pipette inserted into the vagina by the patient without medical supervision were compared with specimens obtained by the usual cervical swab method taken under direct visualization at pelvic examination. With both groups cultures were performed on ThayerMartin VCN medium. Laboratory confirmation of gonorrhoea was obtained in 68 per cent. of these women; in 56 per cent. of all females with gonorrhoea and 70 per cent. of the teenagers, gonorrhoea was confirmed by the pipette method. The last group included two patients with a negative result by cervical culture and one who refused pelvic examination. It is suggested that this method merits further appraisal for the detection of gonorrhoea in asymptomatic, sexually active young females who refuse conventional genital examination or do not seek or receive medical care for venereal disease.

\section{References}

American Social Health Association (1971)

Caldwell, J. G., Price, E. V., Pazin, G. J., and Cornelius, C. E., III (1971) Amer. F. Obstet. Gynec., 109,463

KampmeIER, R. H. (1968). Med. Aspects hum. Sexuality, 2, 14

Lucas, J. B., Price, E. V., Thayer, J. D., and Schroeter, A. L. (1967) New Engl. F. Med., 276, 1454

Martin, J. E., Billings, T. E., Hackney, J. F., and ThaYer, J. D. (1967) Publ. Hlth Rep. (Wash.), 82, 361 - and LESTER, A. (1971) HSMHA Hlth Rep., 86, 30

Merril, J. A. (1968). Med. Aspects hum. Sexuality, 2, 37

Schmale, J. D., Martin, J. E., Jr., and Domescik, G. (1969) f. Amer. med. Ass., 210, 312

SETH, A. (1970) Brit. F. vener. Dis., 46, 201

ThaYer, J. D., and Martin, J. E., Jr. (1966). Publ. Hlth Rep. (Wash.), 81, 559

Essai d'une méthode de détection de la gonococcie, avec l'aide de la malade elle-même, applicable aux femmes craintives

\section{SOMMAIRE}

Une série de 47 femmes présentant des symptômes de gonococcie ou un antécédent de contact gonococcique fut examinée bactériologiquement en vue de mettre la maladie en évidence. Les prélèvements étaient obtenus par l'introduction dans le vagin d'une pipette en matière plastique par la femme elle-même, sans intervention du médecin, et une comparaison fut effectuée avec les prélèvements cervicaux par écouvillons introduits, selon la méthode habituelle, sous contrôle de la vue lors de l'examen gynécologique. Pour les deux groupes, les cultures furent effectuées sur le milieu de Thayer-Martin VCN. Par la méthode de la pipette, la gonococcie fut confirmée au laboratoire chez 68 pour cent de ces femmes, chez 56 pour cent de l'ensemble des femmes gonococciques et 70 pour cent des moins de 20 ans. Dans le dernier groupe figuraient deux malades ayant donné des résultats négatifs à la culture cervicale et une qui avait refusé l'examen gynécologique. On considère que cette méthode mérite une évaluation ultérieure pour la détection de la gonococcie chez les jeunes femmes sexuellement actives, sans symptômes, qui refusent l'examen génital conventionnel ou ne désirent pas ou n'ont pas reçu, pour les maladies vénériennes, l'aide médicale. 